\title{
LIMPACS Workshop: Long-Term Response to Reduced Nutrient Loading
}

Silkeborg, Denmark, January 18-22, 2003

Although climate change holds the attention of both the general public and the science community, other environmental problems are equally important for freshwater ecosystems. The effect of nutrient inputs to aquatic systems was the focus of considerable research in the 1970s and it is now returning to the environmental agenda. The possible negative interplay between climate-driven changes in lakes and nutrients may undo the positive effects of nutrient reduction strategies over the last $15-20$ years at many lakes in Europe and North America (Fig. 1). Reduced nutrient loading (or oligotrophication) brings about substantial changes to lakes but long-term monitoring indicates that these are rarely the simple reverse of those changes that resulted from increased nutrient loading and are often delayed. New quantitative paleolimnological techniques have helped to describe the effects of changing nutrient loadings over much longer time frames than contemporary data have permitted. In an attempt to synthesize the available data, we held a LIMPACSsponsored workshop on the biological effects of reduced nutrient loadings to lakes.

Oligotrophication illustrates the mutual interdependence of sediment-based environmental reconstruction and contemporary limnology. For many lakes, there is no information about their background ecological status so it is difficult to determine whether remedial action is working or not. For those lakes with long-term datasets, continuous monitoring started at the peak of eutrophication problems, as its effects became visible (e.g. algal scums). As a result, long-term records are now often $>20$ years and provide the possibility of validating palaeolimnological reconstructions for both nutrient concentrations and eventually perhaps, whole-system dynamics.

The workshop was attended by 35 people from 15 countries (in-

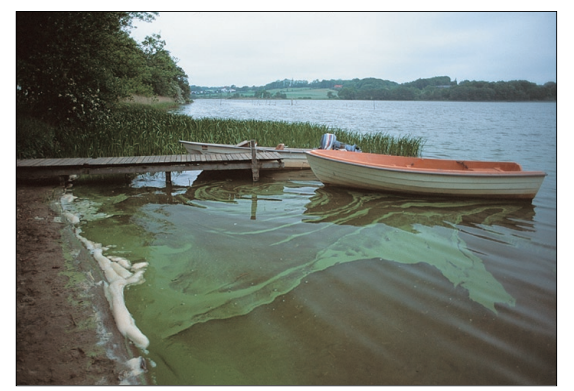

Fig. 1: Many Danish lakes have experienced major reductions in nutrient loadings over the last 20 years - a good reason for holding a LIMAPCS workshop on oligotrophication in Denmark.

cluding China, Estonia, Russia and Hungary as well as the USA, Canada and many EU countries). The range of lake types reflected this diverse geographical context, including coastal Mediterranean lagoons, shallow, sub-tropical Lake Apoka (Florida), small lakes in Northern Europe and large, deep pre-Alpine lakes. The workshop was based around two questionnaires (one for the palaeo-group and one for the contemporary limnology-group) that participants had to complete prior to arrival at the meeting. As well as presentations of individual case studies for those sites where there was long-term data (e.g. Lough Neagh, Lake Constance, Lago Magiorre and Lake Washington), there was considerable discussion on the comparative response of different lake types to nutrient reduction. To what extent is it possible to generalise about the observed responses to nutrient reduction across such a wide range of lake types? Nutrient reduction primarily targets phosphorus. Is the role of nitrogen in lake functioning altered and will it continue to change? Does the sediment record reflect the changes observed in the water column? The answer to these questions will appear in the meeting proceedings that are to be published in a special issue of Freshwater Biology.

LIMPACS is an attempt to create a holistic approach to understanding past and present lake variability and to reduce the largely artificial boundaries between palaeolimnol- ogy and contemporary limnology. The Silkeborg workshop was an important step towards this union, as it included limnologists who had not considered the possible benefits of sediment-based approaches, those who have a foot in both camps and palaeolimnologists who need to understand the complexity of contemporary lake dynamics, and hence avoid limnologically-naive interpretations. The discussion at the meeting was lively and reflected this range of interests.

Oligotrophication has provoked fundamental questions about our understanding of the predictability of lake ecosystems. It provides an opportunity for limnologists to test theories about ecological interactions between different trophic levels and for palaeolimnologists to consider the integrity of the sediment record. There is also considerable relevance for the future, however, as we try to understand the synergism between varying nutrient loads and climate. Oligotrophication is mainly the result of point-source reductions, but modern farming practice and the growth of the agricultural phosphorus surplus means that diffuse phosphorus losses to freshwater will become increasingly important. There is plenty of material for future LIMPACS activities.

The meeting was sponsored by the National Environmental Research Institute (NERI) in Silkeborg, Denmark. PAGES provided funding for the participation of scientists from less developed countries.

\section{N. John Anderson}

Geological Survey of Denmark \& Greenland, Copenhagen; nja@geus.dk

\section{RichaRd W. BatTARbeE}

ECRC, University College London, U.K.; r.batterbee@geog.ucl.ac.uk

Erik Jeppesen

National Environmental Research Institute, Silkeborg, Denmark; ej@dmu.dk 